(2) Open Access Full Text Article

\title{
Resveratrol inhibits transforming growth factor- $\beta 2$-induced epithelial-to-mesenchymal transition in human retinal pigment epithelial cells by suppressing the Smad pathway
}

\author{
This article was published in the following Dove Press journal: \\ Drug Design, Development and Therapy \\ II January 2017 \\ Number of times this article has been viewed
}

\author{
Ching-Long Chen ${ }^{1,2}$ \\ Yi-Hao Chen ${ }^{1,2}$ \\ Ming-Cheng Tai ${ }^{2}$ \\ Chang-Min Liang ${ }^{2}$ \\ Da-Wen Lu' ${ }^{1,2}$ \\ Jiann-Torng Chen ${ }^{1,2}$ \\ 'Graduate Institute of Medical \\ Science, National Defense Medical \\ Center, Taipei, Taiwan; ${ }^{2}$ Department of \\ Ophthalmology, Tri-Service General \\ Hospital, National Defense Medical \\ Center, Taipei, Taiwan
}

\begin{abstract}
Proliferative vitreoretinopathy (PVR) is the main cause of failure following retinal detachment surgery. Transforming growth factor (TGF)- $\beta 2$-induced epithelial-to-mesenchymal transition (EMT) plays an important role in the development of PVR, and EMT inhibition decreases collagen gel contraction and fibrotic membrane formation, resulting in prevention of PVR. Resveratrol is naturally found in red wine and has inhibitory effects on EMT. Resveratrol is widely used in cardioprotection, neuroprotection, chemotherapy, and antiaging therapy. The purpose of this study was to investigate the effects of resveratrol on TGF- $\beta 2$-induced EMT in ARPE-19 cells in vitro. We found that resveratrol suppressed the decrease of zona occludens-1 (ZO-1) and caused an increase of alpha-smooth muscle actin expression in TGF- $\beta 2$-treated ARPE-19 cells, assessed using Western blots; moreover, it also suppressed the decrease in ZO-1 and the increase of vimentin expression, observed using immunocytochemistry. Resveratrol attenuated TGF- $\beta 2$-induced wound closure and cell migration in ARPE-19 cells in a scratch wound test and modified Boyden chamber assay, respectively. We also found that resveratrol reduced collagen gel contraction - assessed by collagen matrix contraction assay - and suppressed the phosphorylation of Smad2 and Smad3 in TGF- 32 -treated ARPE-19 cells. These results suggest that resveratrol mediates anti-EMT effects, which could be used in the prevention of PVR.
\end{abstract}

Keywords: resveratrol, epithelial-to-mesenchymal transition, proliferative vitreoretinopathy, transforming growth factor- $\beta 2$, retinal pigment epithelial cells

\section{Introduction}

Proliferative vitreoretinopathy (PVR), a fibrotic change process that occurs in $5 \%-10 \%$ of all rhegmatogenous retinal detachments (RRDs), is the main cause of failure following primary retinal detachment surgery because PVR leads to a secondary retinal detachment. ${ }^{1}$ It is a clinical entity characterized by the growth and contraction of cellular membranes within the vitreous cavity and on both surfaces of the retina after RRD; ${ }^{2}$ however, despite recent progress in surgical techniques, PVR is still the most common cause of recurring retinal detachment because these membranes exert traction and lead to the reopening of successfully treated retinal breaks, create new retinal breaks, and distort the macula. ${ }^{2,3}$ Recently, anti-inflammatory compounds, antiproliferative agents, and antigrowth factor inhibitors have been tested as major candidate drugs for the pharmacological suppression of PVR, but their poor efficacy and multiple side effects limit their use in adjunctive therapy. ${ }^{1}$ Therefore, investigating the mechanisms that
Correspondence: Jiann-Torng Chen Department of Ophthalmology, Tri-Service General Hospital, National Defense Medical Center, 325 Cheng-Kung Road, Section 2,

Taipei I 14, Taiwan, Republic of China

Tel +886287927163

Fax +88628792 7164

Email jt66chen@gmail.com $\mathrm{BY}$
hereby accept the Terms. Non-commercial uses of the work are permitted without any further permission from Dove Medical Press Limited, provided the work is properly attributed. For permission for commercial use of this work, please see paragraphs 4.2 and 5 of our Terms (https://www.dovepress.com/terms.php). 
cause PVR and developing effective alternative treatments for PVR remain important issues.

The development of PVR is dependent on the migration and proliferation of retinal pigment epithelial (RPE) cells, glial cells, and inflammatory cells. ${ }^{4}$ The RPE cells normally constitute a pigmented monolayer that lies between the neuroretina and the choriocapillaris. ${ }^{5}$ Previous studies demonstrate that RPE cells are present in epiretinal and subretinal membranes and are considered to have a profibrotic role in the development of PVR; ${ }^{6,7}$ however, RPE cells observed in membranes from PVR possess the shape of fibroblasts and participate in fibrosis, thus diverging from the characteristics of epithelial cells. ${ }^{8}$ This transdifferentiation of RPE cells is considered an epithelial-tomesenchymal transition (EMT), which is a biological process wherein epithelial cells lose their differentiated phenotype and become mesenchymal-like cells; RPE cells are also thought to mediate pathological processes such as fibrosis. ${ }^{9}$ Mesenchymal-like RPE cells exhibit an increase in attachment, spreading, migration, and proliferation on the retinal surfaces, in addition to playing an important role in the onset of PVR. ${ }^{3}$ Recent studies report that the EMT of RPE cells is associated with PVR and that this process contributes to the formation of contractile proliferative membranes on the epiretinal or subretinal surfaces..$^{10,11}$

The pathogenesis of PVR is mediated by multiple growth factors and cytokines such as transforming growth factor (TGF)- $\beta$, TGF- $\beta 2$, CTGF, PDGF, EGF, IGF-I, b-FGF, HGF, IL-1 $\beta$, and IL- $6 .{ }^{4,12-15}$ One isoform of TGF- $\beta$, TGF- $\beta 2$, is considered the main player in PVR. ${ }^{3,16}$ TGF- $\beta$ is a multifunctional cytokine that exerts multiple biological effects in the eye, including cell growth, differentiation, promotion of EMT, inflammation, and neovascularization. ${ }^{17}$ TGF- $\beta$ isoforms bind to its receptors, which initiate intracellular signals through activation of downstream mediator Smad proteins. Smad 2 and Smad 3 are phosphorylated by TGF- $\beta$ receptors, then form a complex with Smad4, and are translocated to the nucleus, where they activate the TGF- $\beta$-dependent target genes. ${ }^{18}$ Studies indicate that TGF- $\beta 2$ is the predominant TGF- $\beta$ isoform in the posterior segment of the eye and that inhibition of TGF- $\beta 2$-induced EMT can decrease collagen gel contraction and fibrotic membrane formation, resulting in the prevention of PVR. ${ }^{19,20}$ In addition, recent studies also report that TGF- $\beta 2$ induces phosphorylation of Smad2 and Smad3, which triggers the EMT of RPE cells, as well as increasing the expression of mesenchymal markers (including alpha-smooth muscle actin [ $\alpha$-SMA] and vimentin) and decreasing the expression of epithelial markers such as zona occludens (ZO)-1..$^{21,22}$ In the eyes, TGF- $\beta$-induced EMT has been studied in many cell lines as model systems, including RPE cells, lens epithelial cells, and corneal epithelial cells, wherein blocking TGF- $\beta$ activity at the level of Smad signaling suppresses EMT. ${ }^{17,23}$ Therefore, developing TGF- $\beta$ / Smad signaling inhibitors is a potential therapeutic goal for preventing PVR.

Resveratrol (3,4',5-trihydroxy-trans-stilbene), a polyphenol naturally found in red wine, is widely used as a nutritional therapeutic intervention due to its cardioprotective, neuroprotective, chemotherapeutic, and antiaging effects. ${ }^{24}$ Several studies demonstrate that it exerts many biological effects in the eye, including antioxidative, antiapoptotic, antitumorigenic, anti-inflammatory, antiangiogenic, and vasodilator properties; it plays a critical role in the prevention of ocular diseases, including glaucoma, cataract, diabetic retinopathy, and macular degeneration. ${ }^{24}$ Resveratrol exerts these same protective effects in RPE cells. ${ }^{25-28}$ Although previous studies have reported that resveratrol prevents fibrosis development by suppressing induction of EMT in various cell types, ${ }^{29-31}$ the effect of resveratrol on TGF- $\beta 2$-induced EMT in RPE cells is not clearly understood. Therefore, the purpose of this study was to investigate the effects of resveratrol on TGF- 32 -induced EMT in RPE cells and gain further insight into its mechanism in vitro, so that this knowledge could be used to develop a potential therapeutic approach against PVR by targeting EMT in RPE cells.

\section{Materials and methods RPE cell culture and treatment}

The human RPE cell line ARPE-19 was obtained from the American Type Culture Collection (Manassas, VA, USA). The cell lines were cultured in Dulbecco's modified Eagle's medium (DMEM)-F-12 (Invitrogen-Gibco, Grand Island, NY, USA), supplemented with $4 \mathrm{mM} \mathrm{L-glutamine,} 10 \%$ fetal bovine serum (FBS; Invitrogen-Gibco), $100 \mathrm{U} / \mathrm{mL}$ penicillin, and $100 \mu \mathrm{g} / \mathrm{mL}$ streptomycin (Sigma-Aldrich, St Louis, $\mathrm{MO}, \mathrm{USA}$ ) at $37^{\circ} \mathrm{C}$ in the presence of $5 \% \mathrm{CO}_{2}$. The culture medium was replaced twice per week. In each experiment, for generation of polarized RPE cell cultures, cells were plated at a confluent density of $1.66 \times 10^{5} / \mathrm{cm}^{2}$ and cultured for an additional 7 days, as previously described. ${ }^{32}$ After 7 days, the characteristics of RPE cells, such as tight junction proteins (eg, ZO-1) and RPE differentiation markers (eg, RPE65), were identified by immunofluorescence staining. The monolayer of RPE cells was stimulated with 50 or $100 \mu \mathrm{M}$ of resveratrol (Sigma-Aldrich) for $24 \mathrm{~h}$. Cells were coincubated with or without TGF- $\beta 2$ (10 ng/mL; PeproTech, New York, 
NY, USA) for 24,48 , or $72 \mathrm{~h}$, in the absence and presence of resveratrol, at $37^{\circ} \mathrm{C}$. All experiments were performed in serum-free medium unless otherwise stated.

\section{Cell viability assay}

The viability of cells was tested using 4-[3-(4-iodophenyl)2-(4-nitrophenyl)-2H-5-tetrazolio]-1,3-benzene disulfonate (WST-1; Roche Diagnostics, Indianapolis, IN, USA) assay, according to the manufacturer's instructions. In brief, confluent monolayer cells were incubated with various concentrations $(25,50,100,200,400$, and $800 \mu \mathrm{M})$ of resveratrol (Sigma-Aldrich) in serum-free medium for $24 \mathrm{~h}$, and $10 \mu \mathrm{L}$ of WST-1 reagent was added to the medium in each well. The cells were incubated in a humidified atmosphere at $37^{\circ} \mathrm{C}$ in $5 \% \mathrm{CO}_{2} / 95 \%$ air for $1 \mathrm{~h}$, the multititer plate was shaken thoroughly for $1 \mathrm{~min}$, and the absorbance was read at $450 \mathrm{~nm}$. The background absorbance was measured in wells containing only the dye solution and culture medium. Cell viability data were obtained from at least three experiments with at least six wells at each concentration in separate 96-well plates. The mean optical density values corresponding to the untreated controls were defined as $100 \%$. The results were expressed as the percentage of the optical density of treated cells relative to that of untreated controls.

\section{Western blot analysis}

Confluent cultured cells were preincubated with or without resveratrol and then coincubated with or without TGF- $\beta 2$ in the absence and presence of resveratrol for the indicated periods and dosages at $37^{\circ} \mathrm{C}$. To detect $\alpha$-SMA, ZO- 1 , Smad2, phosphorylated (p)-Smad2, Smad3, p-Smad3, and glyceraldehyde 3-phosphate dehydrogenase (GAPDH) expression at the protein level, the cells were washed twice with phosphate-buffered saline (PBS) and detached by scraping. Cells were pelleted at $1,000 \times g$, resuspended, and sonicated in cold lysis buffer $(50 \mathrm{mM}$ Tris- $\mathrm{HCl}[\mathrm{pH}$ 7.5], $2 \%$ sodium dodecyl sulfate [SDS], and $1 \mathrm{mM}$ phenylmethylsulfonyl fluoride). The insoluble debris was removed by centrifugation at $12,000 \mathrm{~g}$ at $4^{\circ} \mathrm{C}$ for $15 \mathrm{~min}$. The protein concentration was determined using the bicinchoninic acid method (BCA; Pierce, Rockford, IL, USA) with bovine serum albumin (BSA) as the standard. The lysates $(20 \mu \mathrm{g})$ were separated using one-dimensional SDS-polyacrylamide gel electrophoresis. The separated proteins were transferred onto polyvinylidene difluoride membranes (Immobilon; Millipore, Bedford, MA, USA), then blocked with $5 \%(\mathrm{w} / \mathrm{v})$ milk for $1 \mathrm{~h}$ at room temperature, followed by incubation overnight at $4{ }^{\circ} \mathrm{C}$ with antibodies directed against $\alpha$-SMA (Sigma-Aldrich), ZO-1 (Zymed Laboratories, South San Francisco, CA, USA), Smad2 (Cell Signaling Technology, Danvers, MA, USA), p-Smad2, Smad3, p-Smad3, and GAPDH. The antibodies, except those against GAPDH, were diluted 1:1,000 in Tris-buffered saline containing Tween-20 (TBST; $0.1 \%$ at 1×) (Santa Cruz Biotechnology, Santa Cruz, CA, USA). Antibodies against GAPDH were diluted 1:25,000 in TBST (Santa Cruz Biotechnology). The membranes were washed and incubated with a horseradish peroxidase-conjugated secondary antibody (1:25,000; Jackson ImmunoResearch Laboratories, West Grove, PA, USA) for $1 \mathrm{~h}$ at room temperature, and the protein was visualized using an enhanced chemiluminescence (ECL) procedure (ECL; Millipore, Billerica, MA, USA). The images of the Western blots were acquired using a UVP BioSpectrum 500 imaging system and analyzed using VisionWorks ${ }^{\circledR}$ LS software (UVP, Upland, CA, USA).

\section{Immunocytochemistry}

ARPE-19 cells were grown in 12-well tissue culture dishes. Following the resveratrol treatment stated earlier, cells were washed, fixed with $4 \%$ paraformaldehyde, and then treated with $0.1 \%$ Triton X-100 for $10 \mathrm{~min}$ on ice. Cells were further incubated with 5\% BSA in PBS for $1 \mathrm{~h}$ at room temperature. Anti- ZO-1 antibodies (1:100 dilution; Zymed Laboratories) and anti-vimentin antibodies (1:100 dilution; Santa Cruz Biotechnology) were used as primary antibodies. DyLight 488 anti-rabbit immunoglobulin G (IgG) and DyLight 594 anti-mouse IgG antibodies (1:200 dilution; Bethyl Laboratories, Montgomery, TX, USA) were used as secondary antibodies, respectively. Nuclei were counterstained with 4',6'-diamidino-2-phenylindole (Sigma-Aldrich). Preparations were mounted in $70 \%$ glycerol and examined using a fluorescence microscope (CKX41; Olympus Corporation, Tokyo, Japan).

\section{Closure of scratch wound}

A modified in vitro scratch assay was used to evaluate cell migration, as previously described. ${ }^{21,33}$ Briefly, confluent monolayers of ARPE-19 cells were serum-starved for $24 \mathrm{~h}$ and pretreated with $10 \mu \mathrm{g}$ mitomycin-C for $2 \mathrm{~h}$ before inflicting a scratch wound on the monolayer with a P200 pipette tip. The cells were treated with $10 \mathrm{ng} / \mathrm{mL}$ TGF- $\beta 2$ in the presence and absence of 50 or $100 \mu \mathrm{M}$ resveratrol (Sigma-Aldrich), and the cells' ability to migrate and close the wound space was assessed by light microscopy at 24,48 , and $72 \mathrm{~h}$ after the application of the scratch. 


\section{Cell migration assay}

Migration was also measured with a modified Boyden chamber assay, as previously described..$^{21,34}$ Briefly, ARPE- 19 cells were seeded at a density of $5 \times 10^{4}$ cells per well in the upper chamber of a fibronectin-coated 24-well plate with an $8-\mu \mathrm{m}$ transwell pore (Corning Incorporated, Corning, NY, USA). The lower chamber was filled with $0.1 \%$ FBS-DMEM-F12 containing $10 \mathrm{ng} / \mathrm{mL}$ TGF- $\beta 2$ (PeproTech). After $5 \mathrm{~h}$ of incubation, the inserts were washed with PBS, fixed with cold methanol $\left(4^{\circ} \mathrm{C}\right)$ for $10 \mathrm{~min}$, and counterstained with hematoxylin for $20 \mathrm{~min}$. The number of migrated cells was counted by phase-contrast microscopy. Four randomly chosen fields were counted per insert.

\section{Collagen matrix contraction assay}

Collagen matrix contraction was analyzed using a modification of a previously described method. ${ }^{21,35,36}$ Briefly, rat tail type I collagen (Sigma-Aldrich) was dissolved in $0.1 \%$ acetic acid in sterile distilled water and stored at $4{ }^{\circ} \mathrm{C}$ overnight. The 24-well plates were preincubated overnight with $2 \%$ FBS to block nonspecific binding. The ARPE-19 cells $\left(1.0 \times 10^{6} \mathrm{cells} / \mathrm{mL}\right)$ were resuspended in DMEM-F12. The cell suspension was mixed with $5.0 \mathrm{~mL}$ of $3 \mathrm{mg} / \mathrm{mL}$ collagen (rat tail type I collagen) and $3.0 \mathrm{~mL}$ of concentrated serumfree minimal essential medium containing glutamine, antibiotics (100 U/mL penicillin and $100 \mathrm{mg} / \mathrm{mL}$ streptomycin), and $391 \mu \mathrm{L} 1 \mathrm{mM} \mathrm{NaOH}$. The cell-collagen mixture was transferred to the 24 -well plate $(350 \mu \mathrm{L}$ per well) and incubated at $37^{\circ} \mathrm{C}$ for $1 \mathrm{~h}$ to allow polymerization. Collagen gel was detached from the bottom of the wells after $1.5 \mathrm{~h}$, and the matrices were floated in $1 \mathrm{~mL}$ DMEM-F12 containing $10 \%$ FBS. After $24 \mathrm{~h}$, the medium was removed, and the gels were washed with serum-free DMEM-F12 and incubated at $37^{\circ} \mathrm{C}$ for another 3 days in serum-free DMEM-F12 containing $10 \mathrm{ng} / \mathrm{mL}$ TGF- $\beta 2$ with or without resveratrol. The media were changed every other day. Collagen gels without RPE cells were used to calculate baseline contraction. The surface area of each matrix was observed, recorded, and measured digitally on day 3 with a LAS-3000 charge-coupled device (CCD) camera (Fujifilm, Düsseldorf, Germany). The percentage of gel contraction was calculated as [(gel size at day $1-$ gel size at day 3)/gel size at day 1$] \times 100$. This experiment was performed in triplicate.

\section{Statistical analysis}

Normally distributed continuous variables were compared using one-way analysis of variance. When a significant difference between the groups was apparent, multiple comparisons of their mean values were made using Tukey's posthoc test. Data are presented as mean values \pm the standard error of the mean. Each mean represents at least three independent experiments. A $P$-value of 0.05 was used to determine statistical significance. Statistical analyses were performed using GraphPad Prism, version 5.01, for Windows (GraphPad Software, La Jolla, CA, USA).

\section{Results}

\section{Effects of resveratrol on the cell viability of ARPE-I 9 cells}

The cell viability following $24 \mathrm{~h}$ of treatment with resveratrol in ARPE-19 cells was determined by the WST-1 assay, and the results are shown in Figure 1. Cell viability was $97.96 \% \pm 4.8 \%, 97.34 \% \pm 3.93 \%, 95.69 \% \pm 4.82 \%$, $67.86 \% \pm 6.38 \%, 50.15 \% \pm 3.45 \%$, and $19.5 \% \pm 6.96 \%$ following treatment with $25,50,100,200,400$, and $800 \mu \mathrm{M}$ of resveratrol, respectively. The concentrations 200,400 , and $800 \mu \mathrm{M}$ resveratrol led to significant reduction in cell viability $(P<0.001)$ compared with the control group. Half-maximal cytotoxicity of resveratrol on ARPE-19 cells was observed at concentrations of $400-800 \mu \mathrm{M}$. Therefore, 50 and $100 \mu \mathrm{M}$ of resveratrol were selected for our subsequent experiments.

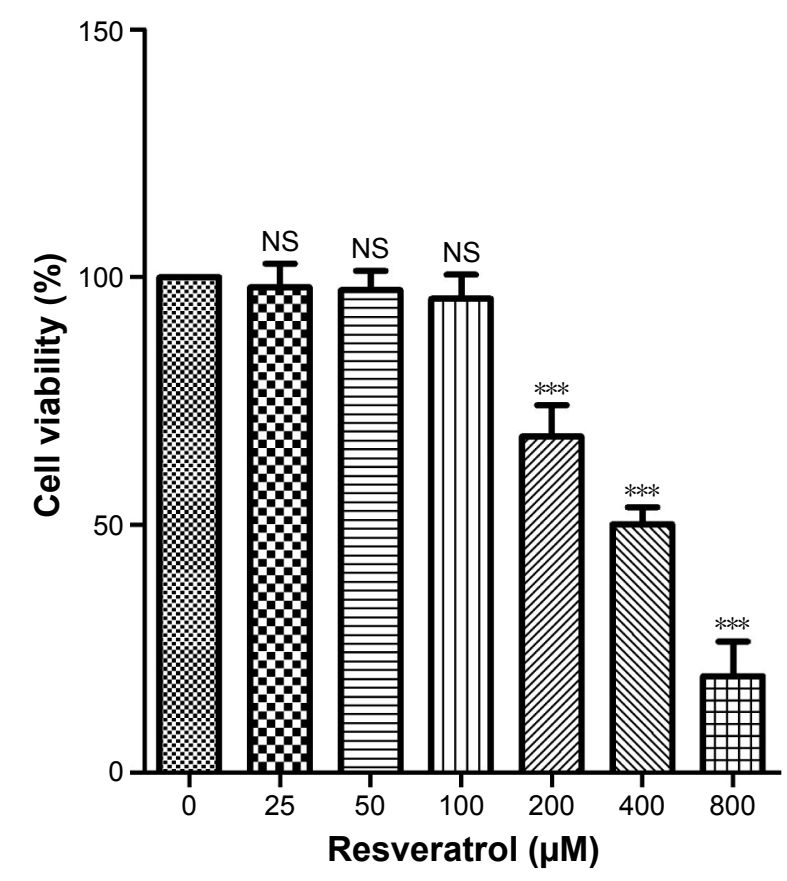

Figure I Effects of resveratrol on the cell viability of ARPE- 19 cells. Notes: The cell viability was determined by the WST-I assay. Confluent monolayer cells were incubated with indicated concentrations of resveratrol $(0,25,50,100$, 200,400 , and $800 \mu \mathrm{M}$, respectively) for $24 \mathrm{~h}$. The results are the mean values \pm SEM of three independent experiments. $* * * P<0.001$ versus the control group.

Abbreviations: NS, not significant; SEM, standard error of the mean; WST, 4-[3(4-iodophenyl)-2-(4-nitrophenyl)-2H-5-tetrazolio]-1,3-benzene disulfonate. 


\section{Effects of resveratrol on the expression of EMT markers ZO-I, $\alpha$-SMA, and} vimentin in TGF- $\beta 2$-treated ARPE- 19 cells

To evaluate the effects of resveratrol on TGF- $\beta 2$-induced EMT of RPE, we used Western blots to examine the protein expression of ZO-1, an epithelial marker, and $\alpha$-SMA, a mesenchymal marker. ${ }^{9}$ As shown in Figure $2 \mathrm{~A}$, TGF- $\beta 2$ significantly suppressed the expression of ZO-1 $(P<0.001)$ in ARPE-19 cells compared to the control group; however, resveratrol treatment reversed this effect in TGF- $\beta 2$-treated ARPE-19 cells. However, TGF- $\beta 2$ significantly stimulated the expression of $\alpha$-SMA, compared to the control group
A
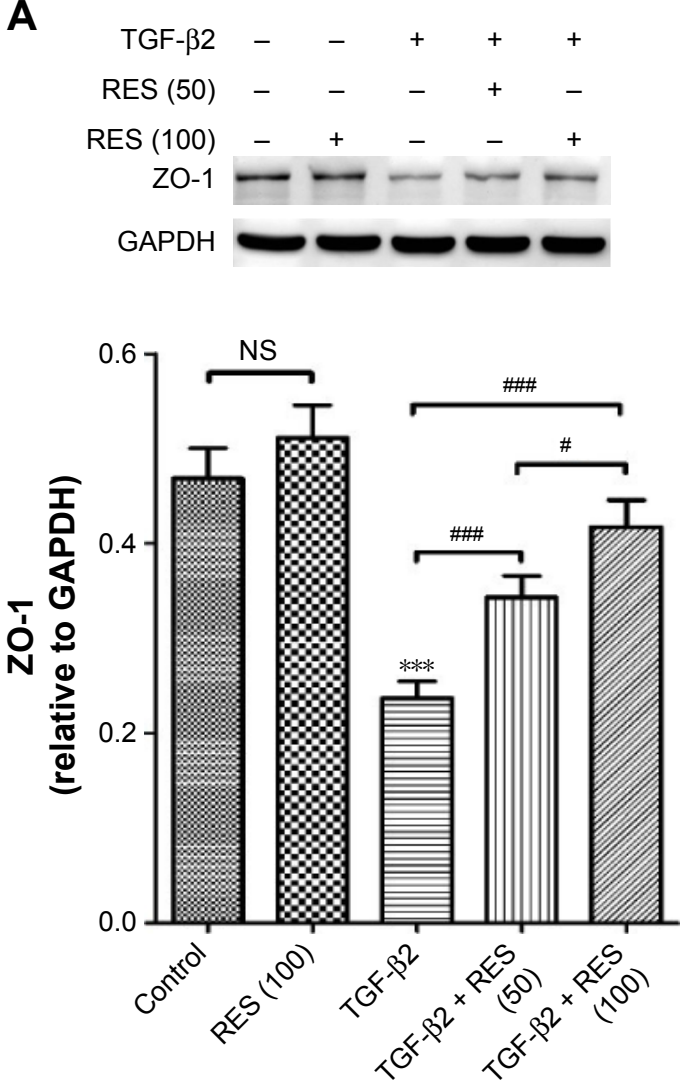

C
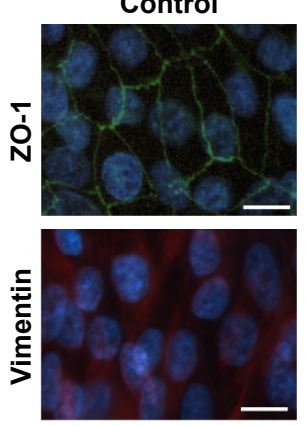

RES (100)
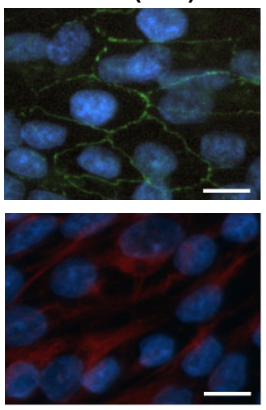

B
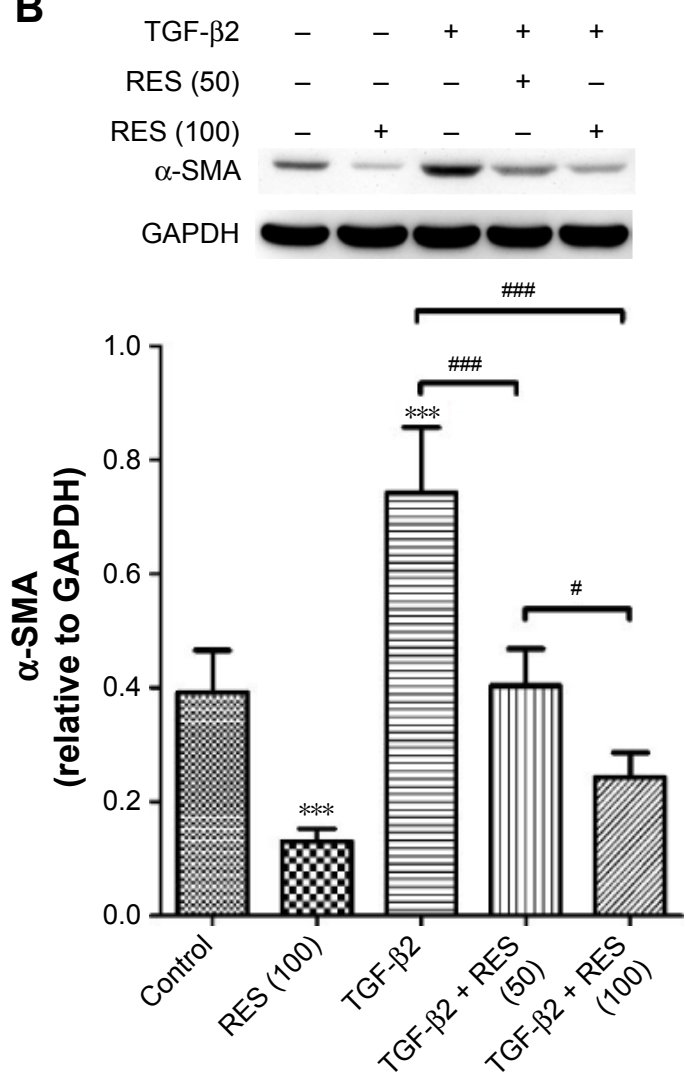

TGF- $\beta 2+$ RES

TGF- $\beta 2$
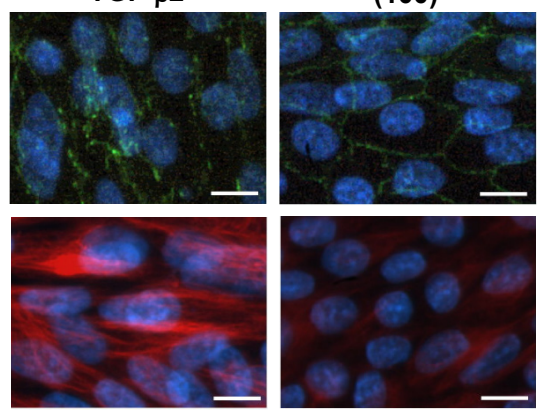

Figure 2 Effects of resveratrol on the expression of ZO-I, $\alpha$-SMA, and vimentin in TGF- $\beta 2$-treated ARPE- 19 cells.

Notes: (A) Comparison of the effects of 50 or $100 \mu \mathrm{M}$ resveratrol on the expression of ZO-I in TGF- $\beta 2$-treated ARPE-19 cells. Cells were pretreated with resveratrol and then treated with TGF- $\beta 2$ in the presence or absence of resveratrol. The results show the mean values \pm SEM of three independent experiments. $* * * P<0.001$ versus the control group; ${ }^{\# P<0.05 ; ~}{ }^{\# P}<0.00$ I. (B) Comparison of the effects of 50 or $100 \mu \mathrm{M}$ resveratrol on the expression of $\alpha$-SMA in TGF- $\beta 2$-treated ARPE-19 cells. Cells were pretreated with resveratrol and then treated with TGF- $\beta 2$ in the presence or absence of resveratrol. The results show the mean values \pm SEM of three independent experiments. ${ }^{* * *} * P<0.00$ I versus the control group; ${ }^{\# P}<0.05 ;{ }^{\# \# P<0.00 I}$. (C) Immunocytochemistry of ARPE- 19 cells after treatment with TGF- $\beta 2$ (I0 ng/mL) for $72 \mathrm{~h}$. Cells were fixed with paraformaldehyde and stained with antibodies against ZO-I and vimentin. Nuclei were counterstained with DAPI. The data are representative of at least three independent experiments. Scale bar: $10 \mu \mathrm{m}$.

Abbreviations: DAPI, 4',6'-diamidino-2-phenylindole; GAPDH, glyceraldehyde 3-phosphate dehydrogenase; NS, not significant; RES, resveratrol; SEM, standard error of the mean; SMA, smooth muscle actin; TGF, transforming growth factor; ZO, zona occludens. 
$(P<0.001)$, whereas resveratrol suppressed the increase of $\alpha$-SMA expression in TGF- $\beta 2$-treated ARPE-19 cells (Figure 2B). Furthermore, we used immunocytochemistry to examine the effects of resveratrol on the expression of ZO-1 and vimentin, another mesenchymal marker, ${ }^{9}$ in TGF- $\beta 2$-treated ARPE-19 cells, using immunofluorescence. Consistent with the results of the Western blotting analysis, TGF- $\beta 2$ reduced ZO-1 expression and increased vimentin expression compared to the control group. In contrast, treatment with resveratrol alleviated the decrease in ZO-1 and increase in vimentin expression in TGF- $\beta 2$-treated ARPE-19 cells (Figure 2C). Taken together, these results demonstrate that treatment with resveratrol suppresses TGF- $\beta 2$-induced EMT in ARPE-19 cells.

\section{Effects of resveratrol on cell migration in TGF- $\beta 2$-treated ARPE- 19 cells}

Resveratrol suppresses the closure of wound space in TGF- $\beta 2$-treated ARPE- 19 cells

TGF- $\beta 2$-induced EMT in RPE cells is an initiating event in many fibrotic processes, including cell migration, proliferation, and contraction of collagen, which occur during the pathogenesis of PVR. ${ }^{37} \mathrm{We}$, therefore, studied the effects of resveratrol on cell migration in TGF- $\beta 2$-treated ARPE-19 cells using a scratch wound method. Cells were starved of serum for $24 \mathrm{~h}$ and pretreated with $10 \mu \mathrm{g}$ mitomycin-C for $2 \mathrm{~h}$ to suppress cell proliferation, as well as being inflicted with a scratch (time 0) and observed at times 0, 24, 48, and $72 \mathrm{~h}$ with or without TGF- $\beta 2$. Treatment with resveratrol alone suppressed wound closure compared to the control group (Figure 3); however, treatment with TGF- $\beta 2$ alone enhanced wound closure in a time-dependent manner. When 50 or $100 \mu \mathrm{M}$ resveratrol was added, it suppressed wound closure in TGF- $\beta 2$-treated ARPE-19 cells. Based on these observations, our results demonstrate that resveratrol inhibits wound closure in TGF- $\beta 2$-treated ARPE-19 cells. Because cell proliferation and migration are essential events in the wound closure process, we used mitomycin-C to suppress cell proliferation, and therefore, these results suggest that resveratrol inhibits TGF- $\beta 2$-induced wound closure by suppressing cell migration.

\section{Resveratrol suppresses TGF- $\beta 2$-induced cell migration in ARPE-19 cells}

As described earlier, we showed that cell migration participated in wound closure in TGF- $\beta 2$-treated ARPE-19 cells, whereas resveratrol attenuated these effects. We next used a modification of the Boyden chamber method to quantify cell migration in TGF- $\beta 2$-treated ARPE-19 cells. Although treatment with resveratrol alone reduced cell migration slightly compared to the control group, this reduction was not statistically significant (Figure 4). Treatment with TGF- $\beta 2$ significantly increased cell migration compared to the control group $(P<0.001)$, while treatment with 50 or $100 \mu \mathrm{M}$

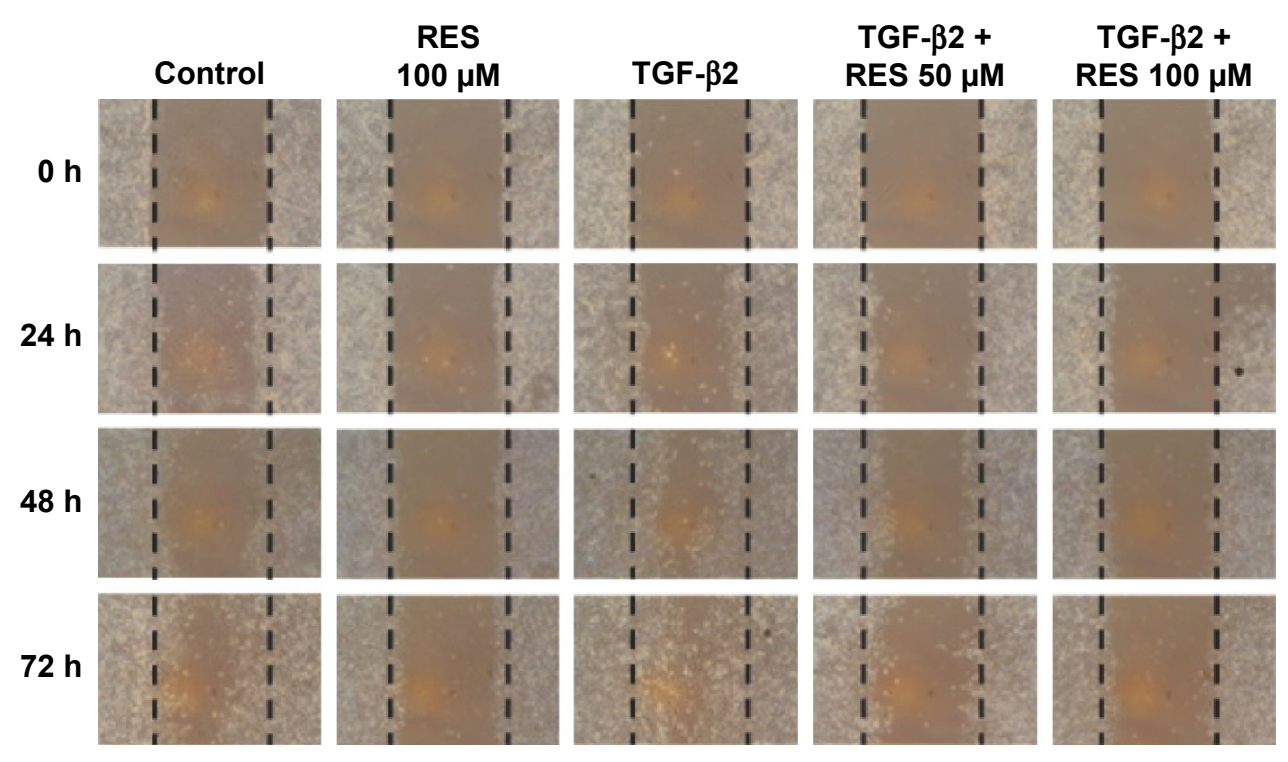

Figure 3 Effects of resveratrol on wound closure in TGF- $\beta 2$-treated ARPE- 19 cells.

Notes: Confluent cells were pretreated with or without resveratrol, scratched, and then treated with TGF- $\beta 2$ in the presence or absence of 50 or I00 $\mu \mathrm{M}$ resveratrol. Light microscopic images of ARPE-19 cells were taken at $0,24,48$, and $72 \mathrm{~h}$ after the infliction of a scratch. The control panel depicts untreated cells. The dashed lines delineate the central observation area and were added by a masked observer to help clarify the extent of migration. Magnification: $\times 100$. The data are representative of at least three independent experiments.

Abbreviations: RES, resveratrol; TGF, transforming growth factor. 


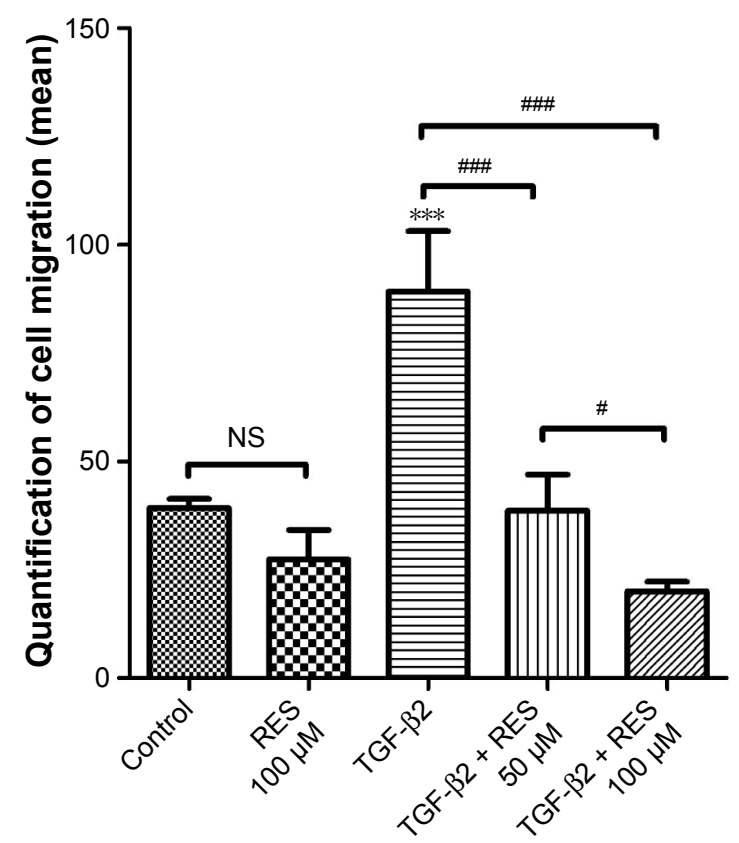

Figure 4 Resveratrol suppresses TGF- $\beta 2$-induced cell migration in ARPE- 19 cells. Notes: Cells were pretreated with or without resveratrol and then treated with TGF- $\beta 2$ in presence or absence of 50 or $100 \mu \mathrm{M}$ resveratrol. The cell migration was quantified using a modified Boyden chamber assay. The results are the mean values \pm SEM of three independent experiments. ${ }^{*} * * P<0.00$ I versus the control

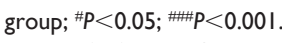

Abbreviations: NS, not significant; RES, resveratrol; SEM, standard error of the mean; TGF, transforming growth factor.

resveratrol significantly attenuated the increase of TGF- $\beta 2$ induced cell migration $(P<0.001)$. Therefore, these results demonstrate that resveratrol suppresses TGF- $\beta 2$-induced cell migration in ARPE-19 cells.
Effects of resveratrol on TGF- $\beta 2$-induced collagen gel contraction in ARPE-19 cells

Given that previous studies have reported that TGF- $\beta 2$ induced collagen gel contraction plays an important role in the pathology of PVR, ${ }^{19,38}$ any inhibition of TGF- $\beta 2$ would dramatically suppress collagen gel contraction in PVR. ${ }^{19}$ In this study, we tested the effects of resveratrol on collagen gel contraction in TGF- $\beta 2$-treated ARPE-19 cells using a collagen matrix contraction assay. We used freshly polymerized collagen matrices containing ARPE-19 cells to measure collagen gel contraction. Cells were incubated with TGF- $\beta 2$ in the presence or absence of resveratrol $(50$ or $100 \mu \mathrm{M})$ for $72 \mathrm{~h}$. Treatment with resveratrol alone did not reduce the percentage of the original area occupied by the cells compared to the control group (Figure 5); however, treatment with TGF- $\beta 2$ significantly reduced the percentage of the original area occupied by the cells compared to the control group $(P<0.001)$. However, treatment with resveratrol significantly attenuated the reduction in the percentage of the original area occupied by TGF- $\beta 2$-treated ARPE-19 cells $(P<0.001)$. Altogether, these results suggest that resveratrol attenuates the effect of collagen gel contraction in TGF- $\beta 2$-treated ARPE-19 cells.

\section{Effects of resveratrol on expression of phosphorylated-Smad2 and -Smad3 in TGF- $\beta 2$-treated ARPE- 19 cells}

The major signaling pathway for TGF- $\beta$ family members is through the phosphorylation of Smad proteins by TGF- $\beta$
A

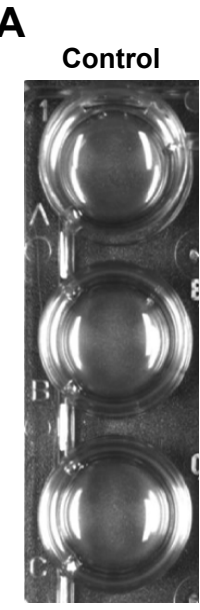

RES

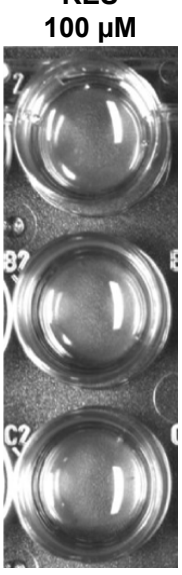

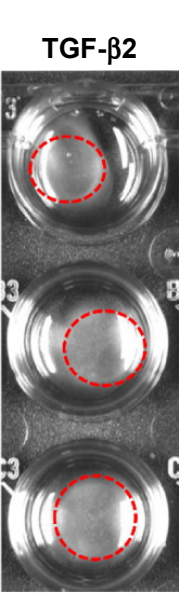
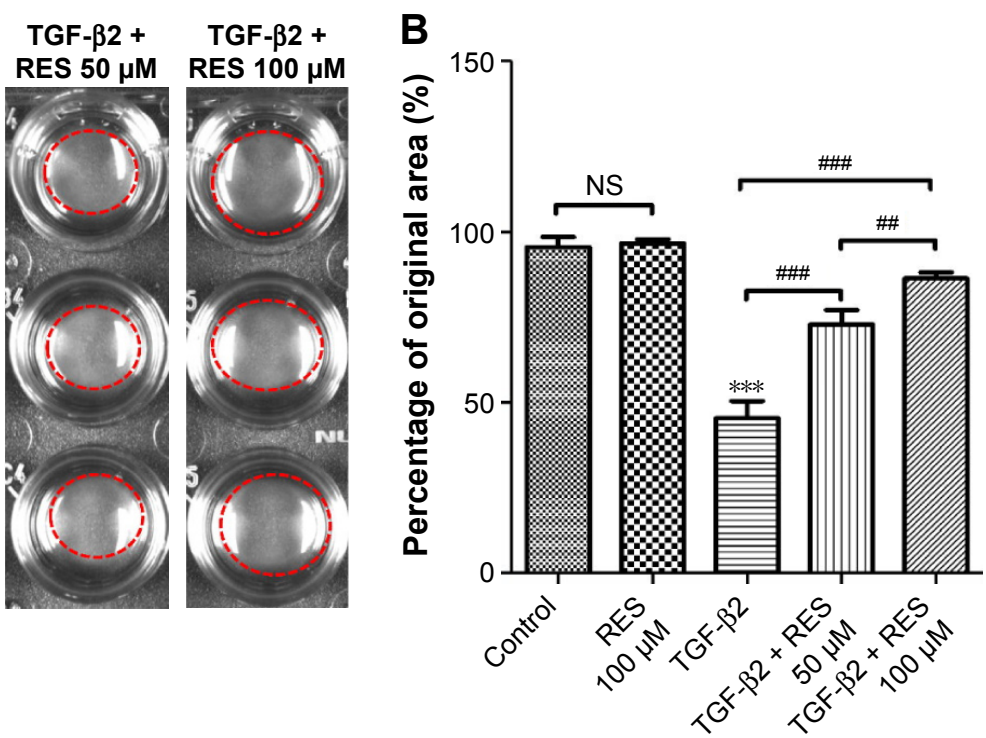

Figure 5 Effects of resveratrol on TGF- $\beta 2$-induced collagen gel contraction in ARPE-19 cells.

Notes: (A) Cells were pretreated with or without resveratrol and then treated with TGF- $\beta 2$ in the presence or absence of 50 or $100 \mu \mathrm{M}$ resveratrol. (B) Contraction or expansion was determined as a percentage of the original area. The results are the mean values \pm SEM of three independent experiments. $* * * P<0.00$ I versus the control group; $\# P<0.01 ;$

Abbreviations: NS, not significant; RES, resveratrol; SEM, standard error of the mean; TGF, transforming growth factor. 
receptor serine/threonine kinase. ${ }^{39}$ A previous study has demonstrated that TGF- $\beta /$ Smad signaling is required for EMT of RPE cells and that it is induced by retinal detachment, while inhibition of the Smad3 pathway prevents the development of PVR in mice. ${ }^{40}$ Furthermore, recent studies have shown that resveratrol acts to suppress EMT and fibrosis specifically by suppressing the TGF- $\beta /$ Smad pathway. ${ }^{29,30,41}$ Considering these studies, we investigated whether resveratrol affects the TGF- $\beta 2$-induced EMT of RPE by suppressing the Smad pathway. We used Western blot analysis to study the effects of resveratrol on the phosphorylation of Smad2 and Smad3, and, thereafter, their expression, in TGF- $\beta 2$ treated ARPE-19 cells. As shown in Figure 6, treatment with TGF- $\beta 2$ significantly increased the expression of $\mathrm{p}-\mathrm{Smad} 2$ and $\mathrm{p}-\mathrm{Smad} 3$ compared to the control group $(P<0.05$ and $P<0.001$, respectively). In addition, treatment with 50 or $100 \mu \mathrm{M}$ resveratrol alleviated the increase of $\mathrm{p}-\mathrm{Smad} 2$ and p-Smad3 expression in TGF- $\beta 2$-treated ARPE-19 cells

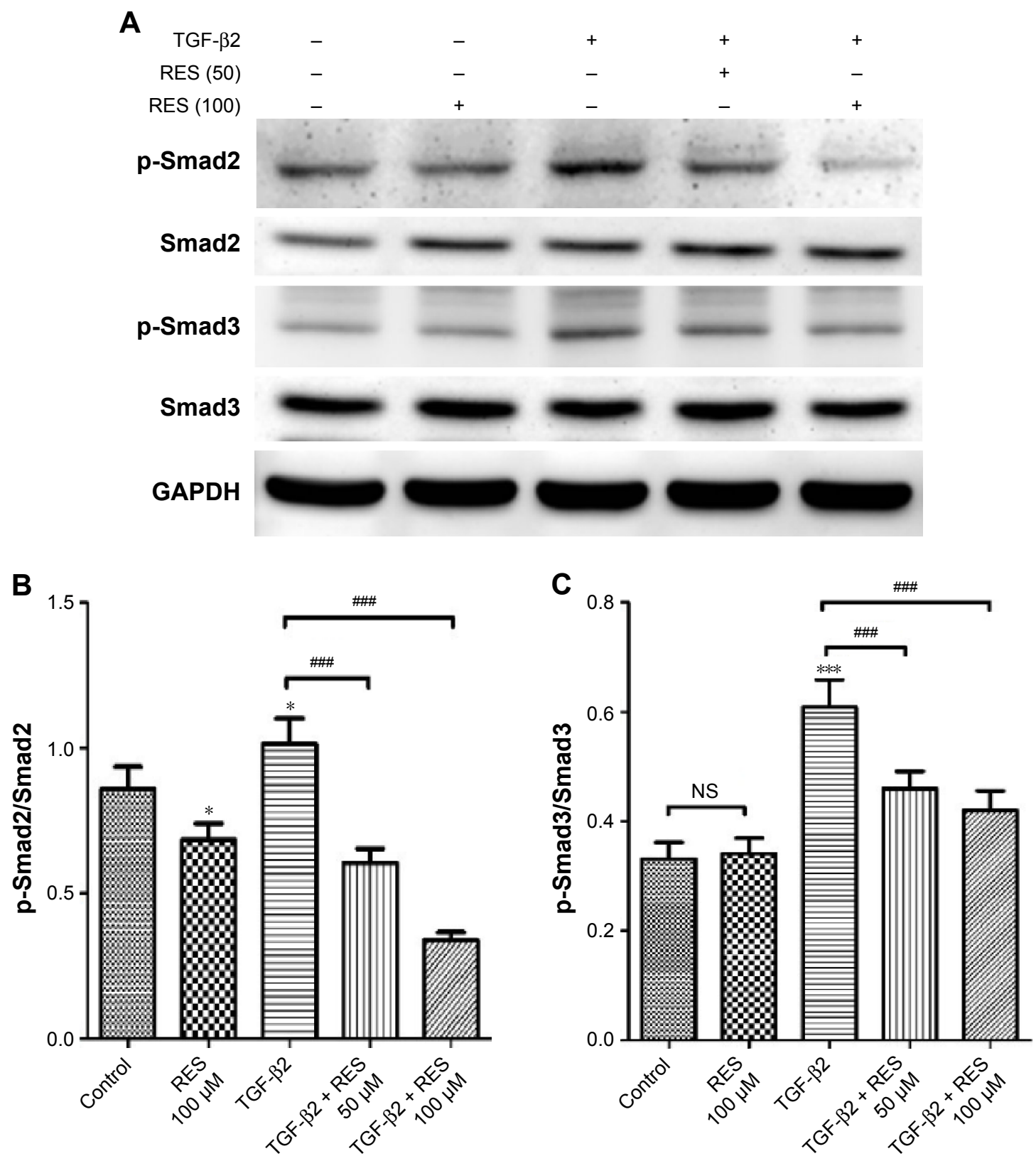

Figure 6 Effects of resveratrol on phosphorylation of Smad2 and Smad3 in TGF-32-treated ARPE-19 cells.

Notes: (A) Cells were pretreated with the indicated concentrations of resveratrol and then treated with TGF- $\beta 2$ in the absence or presence of 50 or $100 \mu$ M resveratrol. Cell lysates were immunoblotted with anti-phosphorylated and anti-total antibodies against Smad2 and Smad3. Protein loading was normalized by using GAPDH as the reference protein. The data are representative of at least three independent experiments. (B, C) Quantitative data for p-Smad2, p-Smad3, Smad2, and Smad3 expression are presented as mean \pm SEM. $* P<0.05$, $* * * P<0.001$ versus the control group; ${ }^{\#} P<0.001$.

Abbreviations: GAPDH, glyceraldehyde 3-phosphate dehydrogenase; NS, not significant; p-Smad2/Smad3, phosphorylated-Smad2/Smad3; RES, resveratrol; SEM, standard error of the mean; TGF, transforming growth factor. 
$(P<0.001)$. Taken together, these results indicate that resveratrol inhibits TGF- $\beta 2$-induced EMT of RPE, at least in part, by suppressing the Smad signaling pathway.

\section{Discussion}

In this study, we investigated the effects of resveratrol on TGF- 32 -induced EMT and the mechanisms underlying its effects in ARPE-19 cells. We demonstrated that resveratrol treatment suppressed the decrease of ZO-1 and increase of $\alpha$-SMA and vimentin expression in TGF- $\beta 2$-treated ARPE-19 cells. Resveratrol attenuated wound closure and cell migration in TGF- $\beta 2$-treated ARPE-19 cells. We also found that collagen gel contraction was alleviated by resveratrol treatment in TGF- $\beta 2$-treated ARPE-19 cells. In addition, we found that resveratrol treatment inhibited the phosphorylation of Smad2 and Smad3 in TGF- $\beta 2$-treated ARPE-19 cells. Based on these data, our results provide evidence for the use of resveratrol as a potential supplement to arrest the development of PVR in vitro.

EMT is associated with fibrosis in multiple organs, such as kidney, lung, and liver. ${ }^{42}$ PVR, a major complication of RRD surgery, is characterized by transdifferentiation of RPE cells through the EMT process. ${ }^{43}$ In addition, TGF- $\beta 2$ is abundant in the vitreous fluid of patients with PVR, and its concentration is significantly correlated with the severity of PVR; ${ }^{16}$ moreover, it is the predominant isoform responsible for the pathogenesis of PVR. ${ }^{19}$ Previous studies have shown that TGF- $\beta 2$ treatment induces EMT of RPE cells, ${ }^{16,22,40,44}$ and that EMT of RPE cells plays a critical role during the exaggerated wound healing process of PVR. ${ }^{42}$ During EMT, RPE cells transdifferentiate from epithelial cells into myofibroblast-like cells, which typically upregulate $\alpha$-SMA and extracellular matrix protein expression, in addition to downregulating ZO-1 and E-cadherin. ${ }^{10,45,46}$ Our previous work also showed that treatment with TGF- $\beta 2$, or TGF- $\beta 1$ plus EGF, in RPE cells increases the expression of $\alpha$-SMA and decreases the expression of ZO-1. ${ }^{21}$ In this study, our data showed that resveratrol treatment attenuated the decrease in ZO-1 expression and increase in $\alpha$-SMA and vimentin expression in TGF- $\beta 2$-treated ARPE-19 cells. Furthermore, previous studies have demonstrated that resveratrol treatment inhibits EMT in multiple in vitro cell models, such as RPE cells, ${ }^{20}$ renal tubular epithelial cells,,${ }^{30}$ human colorectal cancer cell line, ${ }^{41}$ and human non-small-cell lung cancer cells. ${ }^{47}$ Consistent with these studies, ${ }^{20,30,41,47}$ our results also show that resveratrol treatment suppresses TGF- $\beta 2$-induced EMT in ARPE-19 cells.

EMT is a process during which epithelial cells lose their cell-cell adhesion and cell polarity, reorganize their cytoskeleton, and increase the acquisition of migratory and invasive properties. ${ }^{48-50}$ Previous studies have focused on how EMT occurs in various types of epithelial cancers and its association with increased migration, invasion, and metastasis; $;^{30,41,47}$ however, recent evidence has shown that when EMT of RPE cells to a myofibroblastic phenotype occurs, the cells acquire migratory characteristics and participate in epiretinal membrane formation during the clinical evolution of PVR. ${ }^{42}$ Because myofibroblastic RPE cells migrate to the epiretina or subretina, as well as contribute to the formation of the epiretinal or subretinal membrane thereafter, suppressing the migration of myofibroblastic RPE cells is a potential therapeutic target of PVR. ${ }^{21,51,52}$ Previous studies have reported that resveratrol inhibits cell migration by reversing the EMT induced by TGF- $\beta$ in various cell types. ${ }^{41,47,53}$ Therefore, in this study, we examined the effects of resveratrol on cell migration in TGF- $\beta 2$-treated ARPE-19 cells. We found that resveratrol treatment suppressed wound closure and cell migration in TGF- $\beta 2$-treated ARPE-19 cells. Consistent with previous studies, ${ }^{41,47,53}$ these results indicate that resveratrol attenuates the properties of cell migration in myofibroblastic TGF- $\beta 2$-treated ARPE-19 cells.

Because growth and contraction of cellular membranes on both sides of the retinal surfaces can promote retinal detachment, which progressively leads to loss of vision, ${ }^{54}$ contraction of cellular membranes is a key pathogenic step in PVR. Collagen gel contraction is widely used as a model of the wound healing process, and this process is mediated by various cell types, such as fibroblasts and transdifferentiated RPE cells. ${ }^{55-57}$ In addition, a previous study has demonstrated that TGF- $\beta 2$ treatment causes the induction of $\alpha$-SMA and contributes to the formation of stress fibers characteristic of highly contractile myofibroblasts: ${ }^{11}$ collagen gel contraction is also highly correlated with the concentration of activated TGF- $\beta 2$ in the vitreous fluid. ${ }^{19}$ Therefore, we assessed the effects of resveratrol on collagen gel contraction in TGF$\beta 2$-treated ARPE-19 cells. Our results showed that resveratrol suppressed collagen gel contraction in TGF- $\beta 2$-treated ARPE-19 cells. Therefore, these findings support the concept that resveratrol can alleviate the contraction of fibrotic cellular membranes during the pathogenesis of PVR in vitro.

TGF- $\beta$ binds to its receptors to activate multiple downstream pathways, including Smad, Ras and MAP kinase, Rho-like GTPase, and PI3 kinase/Akt signaling. In the Smad-dependent pathway, TGF- $\beta$ induces the activation and phosphorylation of Smad2 and Smad3, following which p-Smad2 and p-Smad3 form trimers with Smad4. These Smad complexes translocate into the nucleus, where they activate or repress the expression of TGF- $\beta$-responsive genes; ${ }^{23}$ 
moreover, they have been conclusively shown to mediate TGF- $\beta$-induced EMT. ${ }^{40}$ Tissue fibrosis and the resulting tissue contraction are critically dependent on the TGF- $\beta$ / Smad signaling pathway; therefore, blocking the Smad signal effectively suppresses fibrogenesis reactions, inhibition of fibroblast-myofibroblast conversion, and EMT. ${ }^{58}$ Connor et $\mathrm{al}^{16}$ demonstrated that deposition of collagen, fibrosis, and EMT are all dependent on Smad3 signaling in a mouse model of retinal detachment. Moreover, recent studies indicate that resveratrol inhibits the TGF- $\beta /$ Smad signaling pathway by downregulating the phosphorylation of Smad2 and/or Smad3 ${ }^{41,59}$ or by deacetylation of Smad4 through SIRT1 activation. ${ }^{20,60}$ In this study, we found that resveratrol could suppress the expression of $\mathrm{p}-\mathrm{Smad} 2$ and $\mathrm{p}-\mathrm{Smad} 3$ in TGF- $\beta 2$-treated ARPE-19 cells. This finding supported the conclusion that resveratrol attenuated EMT, cell migration, and collagen gel contraction in TGF- $\beta 2$-treated ARPE-19 cells through the Smad pathway, at least in part, by suppressing the phosphorylation of $\operatorname{Smad} 2$ and $\operatorname{Smad} 3$.

\section{Conclusion}

Resveratrol effectively inhibits TGF- $\beta 2$-mediated EMT, cell migration, and collagen gel contraction, as well as the phosphorylation of Smad2 and Smad3, which are all key events in the pathogenesis of PVR in vitro. Based on the results of this study, we suggest that resveratrol inhibits several of the downstream events associated with EMT, at least in part, by suppressing the TGF- $\beta 2 /$ Smad signaling pathway in vitro and therefore might be a potential anti-EMT agent in the treatment of PVR.

\section{Acknowledgments}

This research was supported in part by grants NSC-1022314-B-016-046-MY3 and NSC-102-2314-B-016-047 from the National Science Council, grant TSGH-C102-097 from the Tri-Service General Hospital, and grants MOST-1032314-B-016-015 and MOST-105-2314-B-016-045 from the Ministry of Science and Technology.

\section{Disclosure}

The authors report no conflicts of interest in this work.

\section{References}

1. Sadaka A, Giuliari GP. Proliferative vitreoretinopathy: current and emerging treatments. Clin Ophthalmol. 2012;6:1325-1333.

2. Pastor JC. Proliferative vitreoretinopathy: an overview. Surv Ophthalmol. 1998;43(1):3-18.

3. Machemer R. Proliferative vitreoretinopathy (PVR): a personal account of its pathogenesis and treatment. Proctor lecture. Invest Ophthalmol Vis Sci. 1988;29(12):1771-1783.
4. Charteris DG. Proliferative vitreoretinopathy: pathobiology, surgical management, and adjunctive treatment. Br J Ophthalmol. 1995;79(10): 953-960.

5. Strauss $\mathrm{O}$. The retinal pigment epithelium in visual function. Physiol Rev. 2005;85(3):845-881.

6. Hiscott PS, Grierson I, McLeod D. Retinal pigment epithelial cells in epiretinal membranes: an immunohistochemical study. Br JOphthalmol. 1984;68(10):708-715.

7. Hiscott P, Morino I, Alexander R, Grierson I, Gregor Z. Cellular components of subretinal membranes in proliferative vitreoretinopathy. Eye (Lond). 1989;3(pt 5):606-610.

8. Lee SC, Kwon OW, Seong GJ, Kim SH, Ahn JE, Kay ED. Epitheliomesenchymal transdifferentiation of cultured RPE cells. Ophthalmic Res. 2001;33(2):80-86.

9. Kalluri R, Weinberg RA. The basics of epithelial-mesenchymal transition. J Clin Invest. 2009;119(6):1420-1428.

10. Hiscott P, Sheridan C, Magee RM, Grierson I. Matrix and the retinal pigment epithelium in proliferative retinal disease. Prog Retin Eye Res. 1999;18(2):167-190.

11. Tamiya S, Liu L, Kaplan HJ. Epithelial-mesenchymal transition and proliferation of retinal pigment epithelial cells initiated upon loss of cell-cell contact. Invest Ophthalmol Vis Sci. 2010;51(5):2755-2763.

12. Cassidy L, Barry P, Shaw C, Duffy J, Kennedy S. Platelet derived growth factor and fibroblast growth factor basic levels in the vitreous of patients with vitreoretinal disorders. Br J Ophthalmol. 1998;82(2):181-185.

13. Kon CH, Occleston NL, Aylward GW, Khaw PT. Expression of vitreous cytokines in proliferative vitreoretinopathy: a prospective study. Invest Ophthalmol Vis Sci. 1999;40(3):705-712.

14. Hinton DR, He S, Jin ML, Barron E, Ryan SJ. Novel growth factors involved in the pathogenesis of proliferative vitreoretinopathy. Eye (Lond). 2002;16(4):422-428.

15. He S, Chen Y, Khankan R, et al. Connective tissue growth factor as a mediator of intraocular fibrosis. Invest Ophthalmol Vis Sci. 2008; 49(9):4078-4088.

16. Connor TB Jr, Roberts AB, Sporn MB, et al. Correlation of fibrosis and transforming growth factor-beta type 2 levels in the eye. J Clin Invest. 1989;83(5):1661-1666.

17. Saika S. TGFbeta pathobiology in the eye. Lab Invest. 2006;86(2): 106-115.

18. ten Dijke P, Hill CS. New insights into TGF-beta-Smad signalling. Trends Biochem Sci. 2004;29(5):265-273.

19. Kita T, Hata Y, Arita R, et al. Role of TGF-beta in proliferative vitreoretinal diseases and ROCK as a therapeutic target. Proc Natl Acad Sci US A. 2008;105(45):17504-17509.

20. Ishikawa $\mathrm{K}, \mathrm{He} \mathrm{S}$, Terasaki H, et al. Resveratrol inhibits epithelialmesenchymal transition of retinal pigment epithelium and development of proliferative vitreoretinopathy. Sci Rep. 2015;5:16386.

21. Liang CM, Tai MC, Chang YH, et al. Glucosamine inhibits epithelialto-mesenchymal transition and migration of retinal pigment epithelium cells in culture and morphologic changes in a mouse model of proliferative vitreoretinopathy. Acta Ophthalmol. 2011;89(6):e505-e514.

22. Lee H, O'Meara SJ, O'Brien C, Kane R. The role of gremlin, a BMP antagonist, and epithelial-to-mesenchymal transition in proliferative vitreoretinopathy. Invest Ophthalmol Vis Sci. 2007;48(9):4291-4299.

23. Xu J, Lamouille S, Derynck R. TGF-beta-induced epithelial to mesenchymal transition. Cell Res. 2009;19(2):156-172.

24. Abu-Amero KK, Kondkar AA, Chalam KV. Resveratrol and ophthalmic diseases. Nutrients. 2016;8(4):200.

25. King RE, Kent KD, Bomser JA. Resveratrol reduces oxidation and proliferation of human retinal pigment epithelial cells via extracellular signal-regulated kinase inhibition. Chem Biol Interact. 2005;151(2): 143-149.

26. Alex AF, Spitznas M, Tittel AP, Kurts C, Eter N. Inhibitory effect of epigallocatechin gallate (EGCG), resveratrol, and curcumin on proliferation of human retinal pigment epithelial cells in vitro. Curr Eye Res. 2010;35(11):1021-1033. 
27. Mansoor S, Gupta N, Patil AJ, et al. Inhibition of apoptosis in human retinal pigment epithelial cells treated with benzo(e)pyrene, a toxic component of cigarette smoke. Invest Ophthalmol Vis Sci. 2010;51(5): 2601-2607.

28. Pintea A, Rugina D, Pop R, Bunea A, Socaciu C, Diehl HA. Antioxidant effect of trans-resveratrol in cultured human retinal pigment epithelial cells. J Ocul Pharmacol Ther. 2011;27(4):315-321.

29. Zhang YQ, Liu YJ, Mao YF, Dong WW, Zhu XY, Jiang L. Resveratrol ameliorates lipopolysaccharide-induced epithelial mesenchymal transition and pulmonary fibrosis through suppression of oxidative stress and transforming growth factor-beta1 signaling. Clin Nutr. 2015; 34(4):752-760.

30. Bai Y, Lu H, Wu C, et al. Resveratrol inhibits epithelial-mesenchymal transition and renal fibrosis by antagonizing the hedgehog signaling pathway. Biochem Pharmacol. 2014;92(3):484-493.

31. Li J, Qu X, Ricardo SD, Bertram JF, Nikolic-Paterson DJ. Resveratrol inhibits renal fibrosis in the obstructed kidney: potential role in deacetylation of Smad3. Am J Pathol. 2010;177(3):1065-1071.

32. Dunn KC, Aotaki-Keen AE, Putkey FR, Hjelmeland LM. ARPE-19, a human retinal pigment epithelial cell line with differentiated properties. Exp Eye Res. 1996;62(2):155-169.

33. Liang CC, Park AY, Guan JL. In vitro scratch assay: a convenient and inexpensive method for analysis of cell migration in vitro. Nat Protoc. 2007;2(2):329-333.

34. He PM, He S, Garner JA, Ryan SJ, Hinton DR. Retinal pigment epithelial cells secrete and respond to hepatocyte growth factor. Biochem Biophys Res Commun. 1998;249(1):253-257.

35. Mazure A, Grierson I. In vitro studies of the contractility of cell types involved in proliferative vitreoretinopathy. Invest Ophthalmol Vis Sci. 1992;33(12):3407-3416.

36. Eibl KH, Banas B, Schoenfeld CL, et al. Alkylphosphocholines inhibit proliferation of human retinal pigment epithelial cells. Invest Ophthalmol Vis Sci. 2003;44(8):3556-3561.

37. Tosi GM, Marigliani D, Romeo N, Toti P. Disease pathways in proliferative vitreoretinopathy: an ongoing challenge. J Cell Physiol. 2014; 229(11):1577-1583.

38. Hirayama K, Hata Y, Noda Y, et al. The involvement of the rhokinase pathway and its regulation in cytokine-induced collagen gel contraction by hyalocytes. Invest Ophthalmol Vis Sci. 2004;45(11): 3896-3903.

39. Dijke PT, Hill CS. New insights into TGF- $\beta$-Smad signalling. Trends Biochem Sci. 2004;29(5):265-273.

40. Saika S, Kono-Saika S, Tanaka T, et al. Smad3 is required for dedifferentiation of retinal pigment epithelium following retinal detachment in mice. Lab Invest. 2004;84(10):1245-1258.

41. Ji Q, Liu X, Han Z, et al. Resveratrol suppresses epithelial-tomesenchymal transition in colorectal cancer through TGF-beta1/ Smads signaling pathway mediated Snail/E-cadherin expression. $B M C$ Cancer. 2015;15:97.

42. Kalluri R, Neilson EG. Epithelial-mesenchymal transition and its implications for fibrosis. J Clin Invest. 2003;112(12):1776-1784.
43. Pratt $\mathrm{CH}$, Vadigepalli R, Chakravarthula P, Gonye GE, Philp NJ, Grunwald GB. Transcriptional regulatory network analysis during epithelial-mesenchymal transformation of retinal pigment epithelium. Mol Vis. 2008;14:1414-1428.

44. Choudhury P, Chen W, Hunt RC. Production of platelet-derived growth factor by interleukin-1 beta and transforming growth factorbeta-stimulated retinal pigment epithelial cells leads to contraction of collagen gels. Invest Ophthalmol Vis Sci. 1997;38(5):824-833.

45. Casaroli-Marano RP, Pagan R, Vilaro S. Epithelial-mesenchymal transition in proliferative vitreoretinopathy: intermediate filament protein expression in retinal pigment epithelial cells. Invest Ophthalmol Vis Sci. 1999;40(9):2062-2072.

46. Grisanti S, Guidry C. Transdifferentiation of retinal pigment epithelial cells from epithelial to mesenchymal phenotype. Invest Ophthalmol Vis Sci. 1995;36(2):391-405.

47. Wang H, Zhang H, Tang L, et al. Resveratrol inhibits TGF-beta1induced epithelial-to-mesenchymal transition and suppresses lung cancer invasion and metastasis. Toxicology. 2013;303:139-146.

48. Thiery JP, Sleeman JP. Complex networks orchestrate epithelialmesenchymal transitions. Nat Rev Mol Cell Biol. 2006;7(2):131-142.

49. Thiery JP, Acloque H, Huang RY, Nieto MA. Epithelial-mesenchymal transitions in development and disease. Cell. 2009;139(5):871-890.

50. Lamouille S, Xu J, Derynck R. Molecular mechanisms of epithelialmesenchymal transition. Nat Rev Mol Cell Biol. 2014;15(3):178-196.

51. Umazume K, Liu L, Scott PA, et al. Inhibition of PVR with a tyrosine kinase inhibitor, dasatinib, in the swine. Invest Ophthalmol Vis Sci. 2013; 54(2):1150-1159

52. Cheng HC, Ho TC, Chen SL, Lai HY, Hong KF, Tsao YP. Troglitazone suppresses transforming growth factor beta-mediated fibrogenesis in retinal pigment epithelial cells. Mol Vis. 2008;14:95-104.

53. Li W, Ma J, Ma Q, et al. Resveratrol inhibits the epithelial-mesenchymal transition of pancreatic cancer cells via suppression of the PI-3K/Akt/ NF-kappaB pathway. Curr Med Chem. 2013;20(33):4185-4194.

54. Ryan SJ. The pathophysiology of proliferative vitreoretinopathy in its management. Am J Ophthalmol. 1985;100(1):188-193.

55. Rhee S. Fibroblasts in three dimensional matrices: cell migration and matrix remodeling. Exp Mol Med. 2009;41(12):858-865.

56. Morales SA, Mareninov S, Wadehra M, et al. FAK activation and the role of epithelial membrane protein 2 (EMP2) in collagen gel contraction. Invest Ophthalmol Vis Sci. 2009;50(1):462-469.

57. Kimura K, Orita T, Fujitsu Y, et al. Inhibition by female sex hormones of collagen gel contraction mediated by retinal pigment epithelial cells. Invest Ophthalmol Vis Sci. 2014;55(4):2621-2630.

58. Saika S, Yamanaka O, Okada Y, et al. TGF beta in fibroproliferative diseases in the eye. Front Biosci (Schol Ed). 2009;1:376-390.

59. Kim KH, Back JH, Zhu Y, et al. Resveratrol targets transforming growth factor-beta2 signaling to block UV-induced tumor progression. J Invest Dermatol. 2011;131(1):195-202.

60. Simic P, Williams EO, Bell EL, Gong JJ, Bonkowski M, Guarente L. SIRT1 suppresses the epithelial-to-mesenchymal transition in cancer metastasis and organ fibrosis. Cell Rep. 2013;3(4):1175-1186.

\section{Publish your work in this journal}

Drug Design, Development and Therapy is an international, peerreviewed open-access journal that spans the spectrum of drug design and development through to clinical applications. Clinical outcomes, patient safety, and programs for the development and effective, safe, and sustained use of medicines are the features of the journal, which

\section{Dovepress}

has also been accepted for indexing on PubMed Central. The manuscript management system is completely online and includes a very quick and fair peer-review system, which is all easy to use. Visit http://www.dovepress.com/testimonials.php to read real quotes from published authors. 